\title{
A review on numerical and experimental results of hydrogen addition to natural gas in internal combustion engines
}

\author{
Javad Zareei ${ }^{1,2,}$, Faizal Wan Mahmood ${ }^{2}$, Shahrir Abdullah ${ }^{2}$, Yusoff Ali $^{2}$ \\ ${ }^{1}$ Department of Automotive Engineering, Faculty of Mechanical Engineering, Standard Research Institute, Tehran, Iran \\ ${ }^{2}$ Centre for automotive research, Faculty of Engineering \& the Built Environment, University Kebangsaan Malaysia
}

\section{Email address:}

ja_zareei@iust.ac.ir (J. Zareei)

\section{To cite this article:}

Javad Zareei, Faizal Wan Mahmood, Shahrir Abdullah, Yusoff Ali. A Review on Numerical and Experimental Results of Hydrogen Addition to Natural Gas in Internal Combustion Engines. International Journal of Renewable and Sustainable Energy.

Vol. 3, No. 1, 2014, pp. 6-12. doi: 10.11648/j.ijrse.20140301.12

\begin{abstract}
Conventional fossil fuel for combustion system, such as gasoline and petroleum have long been recognized as powerful energy source, however these have a number of problems related to emissions and energy security. The use of hydrogen blends with natural gas is a viable alternative to pure fossil fuels because of the expected reduction of the total pollutant emissions and increase of efficiency. Enhancement of chemical reaction with hydrogen addition is regarded as the increase of $\mathrm{H}, \mathrm{O}$ and $\mathrm{OH}$ free radical mole fraction in the flame. Also in SI engines will move the lean limit to leaner mixture, increasing the combustion speed and temperature. Results show that the hydrogen has a catalyzing effect in the ignition of hydrocarbons with only a few percent addition of hydrogen by volume and by adding it to the pure natural gas (CNG) this difference in spark advance of the engine may be reduced, as a result of the higher flame speed of hydrogen. In this paper, we present the advances and development made on internal combustion engines which operate with mixture of hydrogen/CNG, doing more emphasis in the combustion process, ignition energy and injection systems. Also this paper mentions a comparison that experimental and numerical results match quite well expect for extremely fuel lean condition. The nozzle geometry has an important influence on injection process and combustion development and shows that degree of conicity can be evaluated for each nozzle by the K- Factor.
\end{abstract}

Keywords: Combustion, Hydrogen, Natural Gas, Injection, Performance, Emission

\section{Introduction}

Most of the energy used in the world is supplied by fossil fuels. Burning of the fossil fuels generates waste materials, mainly emissions to the atmosphere in the form of combustion fuel gases and dust, as well as some ash and/or clinker. These waste materials have hazardous effects on the environment, some of them locally, others with more widespread or even global impact [1].

It is well known that vehicles with natural gas (NG) present lower pollutant and carbon dioxide emissions compared to gasoline vehicles [2] and running the natural gas engine lean has many advantages, such as higher efficiency and lower heat losses but as the engine runs close to the so- called lean limit, problems may occur- such as misfiring. In fact, the homogeneous spark-ignited natural gas engine has a lower volumetric efficiency since NG occupies a fraction of intake charge which results in a decrement of the fresh air into the cylinder and thus of the output power [3]. The direct injection has the advantage to eliminate the loss in volumetric efficiency since $\mathrm{NG}$ is directly injected into the cylinder. Anyway, NG engines show a lower efficiency than diesel engines [4].

Natural gas and hydrogen blends can be a viable alternative to pure fossil fuels because of the expected reduction of the total pollutant emissions. These blends offer a valid opportunity for dealing with a sustainable development in transportation sector, in view of the future more stringent emission limits for road vehicles in European Countries. The problem of pollution is especially felt in great urban areas, where cars and heavy duty vehicles strongly contribute to total pollutant emissions [5].

Fuel mixtures of $\mathrm{NG}$ and hydrogen have been widely studied in IC engines [6-11] and their results show that, for lean conditions, the engine performance can improve and the 
$\mathrm{HC}$ and $\mathrm{CO}$ exhaust emissions can be reduced by adding a small amount of hydrogen. At relatively rich conditions some approaches have to be assumed because the NOx emissions increase due to the increment in the adiabatic flame temperature. Some of studies carried out are as below:

Biagio M \& Andrea U. [5] carried out a numerical investigation on SI by using natural gas- hydrogen blend [HCNG10 and HCNG30]. By employing the same spark advance for $\mathrm{CNG}$ and $\mathrm{HCNG}$ fuels, the main result was the negligible variation of the engine brake efficiency in spite of a faster combustion rate. Instead, at MBT spark advance both HCNG 10 and 30 have shown relevant increments of the engine efficiency, especially at low loads. At $25 \%$ engine load the increment of efficiency is about 3\% and $4.5 \%$ for HCNG 10 and 30, respectively [12].

Hoekstra et al [13] observed that experimental results of natural gas fuelled internal combustion engines claiming that hydrogen as additive in NG can strongly improve the performance of such engines, especially in terms of power, efficiency and emissions allowing the engine to work with leaner mixtures. In addition, hydrogen does not affect the anti-knocking performance of $\mathrm{NG}$ fuel and a strong reduction of NOx for hydrogen percentage up to $30 \%$, and important point was the increment of the flame speed propagation and a consequent reduction of the spark advance angle to obtain the Maximum Brake Torque, as already indicated by Nagalingam et al. [14].

Dimopoulos et al. [15] carried out a well-to-wheel assessment for an HCNG engine. He related the engine tests' results with different hydrogen producing methods and concluded that the application

of hydrogen to IC engines is helpful to reduce green house gas emissions. Apostolescu and Chiriac [16] studied the effect of hydrogen addition on the combustion process at mid-to-low loads; results show that the cyclic variation and $10-90 \%$ burn duration were greatly reduced when hydrogen mass fraction varied from $1.5 \%$ to $3 \%$.

\section{Numerical Analysis and Modeling}

The combustion process is analyzed with a two-zone model in this model, the cylinder charge during combustion is assumed to be divided into unburned and burned zones. At each time step, a mixture of fuel and air is transferred from the unburned zone to the burned zone. The two zones are recognized as homogeneous ideal gas and have uniform properties. Unburned gas is consisted of air, $\mathrm{H}$ and $\mathrm{CH}_{4}$, ignoring the residual gas. The amount of fuel-air mixture that is transferred to the burned zone is defined by the burn rate. Once the unburned fuel and associated air has been transferred from the unburned zone to the burned zone in a given time step, a chemical equilibrium calculation is carried out for the entire "lumped" burned zone. This calculation takes into account all of the atoms of each species $(\mathrm{C}, \mathrm{H}, \mathrm{O}$, $\mathrm{N})$ present in the burned zone at that time, and obtains from these an equilibrium concentration of the 11 products of combustion species $\left(\mathrm{N}_{2}, \mathrm{O}_{2}, \mathrm{H}_{2} \mathrm{O}, \mathrm{CO}_{2}, \mathrm{CO}, \mathrm{H}_{2}, \mathrm{~N}, \mathrm{O}, \mathrm{H}, \mathrm{NO}\right.$,
$\left.\mathrm{NO}_{2}, \mathrm{OH}\right)$. The equilibrium concentrations of the species depend strongly on the current burned zone temperature and to a lesser degree, the pressure [17-21].

The following energy equations were solved separately for each time step in each zone and energy conservation equations, detailed control equations for the two-zone thermodynamic model can be derived, which are listed below.

$$
\begin{array}{r}
\frac{d\left(m_{u} e_{u}\right)}{d t}=-p \frac{d v_{u}}{d t}-Q_{u}-\left(\frac{d m_{f}}{d t} h_{f}+\frac{d m_{a}}{d t} h_{a}\right)+\frac{d m_{f, i}}{d t} \\
\frac{d\left(m_{b} e_{b}\right)}{d t}=-p \frac{d v_{b}}{d t}-Q_{b}-\left(\frac{d m_{f}}{d t} h_{f}+\frac{d m_{a}}{d t} h_{a}\right)
\end{array}
$$

The laminar flame speed, $\mathbf{S}_{\mathrm{I}}$ is usually calculated from the equation,

$$
\begin{aligned}
& S_{L}=\left(B_{m}+B_{\phi}\left(\phi-\phi_{m}\right)^{2}\right) \times\left(\frac{T_{u}}{T_{\text {ref }}}\right)^{a}\left(\frac{p}{p_{\text {ref }}}\right){ }^{\beta} \times \\
& (1-2.06(\text { Dilution }) \\
& D E M \times 0.77
\end{aligned}
$$

Where $B_{m}$ and $B_{\phi}$ represent the maximum laminar speed and the laminar speed roll- off value, respectively.

In below equations, each composition of the cylinder charge is considered as ideal gas which means that their specific heats are only dependent on temperature.

$$
\left.\begin{array}{c}
\frac{d T_{u}}{d \theta}=\frac{1}{m_{u} C_{p u}}\left(v_{u} \frac{d p}{d \theta}+\frac{d Q_{u}}{d \theta}\right) \\
\frac{d T_{b}}{d \theta}=\frac{1}{m_{u} C_{p u}}\left[\begin{array}{l}
P \frac{d V}{d \theta}-\left(R_{b} T_{b}-R_{u} T_{u}\right) \frac{d m_{b}}{d \theta}-\frac{R_{u}}{C_{p u}} \\
\left(V_{u} \frac{d P}{d \theta}+\frac{d Q_{u}}{d \theta}\right)+V \frac{d P}{d \theta}
\end{array}\right] \\
\frac{d P}{d \theta}=\frac{1}{\frac{C_{v u}}{C_{p u}} V_{u}-\frac{C_{v b} R_{u}}{R_{b} C_{p u}}+\frac{C_{v b}}{R_{b}} V} \\
\left(1+\frac{C_{v b}}{R_{b}}\right) P \frac{d V}{d \theta}-\frac{d Q}{d \theta}+ \\
{\left[\begin{array}{l}
\left(u_{b}-u_{u}\right)-C_{v b}\left(T_{b}-\frac{R_{u}}{R_{b}} T_{u}\right) \\
+\left(\frac{C_{v b}}{C_{p u}}-\frac{C_{v b} R u}{R_{b} C_{p u}}\right) \frac{d Q_{u}}{d \theta}
\end{array}\right.}
\end{array}\right\}
$$

In the above equations, the subscript $\mathrm{u}$ means unburned zone and $\mathrm{b}$ means burnt zone.

\section{Wide Range of Flammability}

Hydrogen has a wide flammability range in comparison with all other fuels. As a result, hydrogen can be combusted in an internal combustion engine over a wide range of fuel-air mixtures. A significant advantage of this is that hydrogen can run on a lean mixture. A lean mixture is one 
in which the amount of fuel is less than the theoretical, stoichiometric or chemically ideal amount needed for combustion with a given amount of air. This is why it is fairly easy to get an engine to start on hydrogen. Table 1 shows some properties for hydrogen and other fuels.

Generally, fuel economy is greater and the combustion reaction is more complete when a vehicle is run on a lean mixture. Additionally, the final combustion temperature is generally lower, reducing the amount of pollutants, such as nitrogen oxides, emitted in the exhaust. There is a limit to how lean the engine can be run, as lean operation can significantly reduce the power output due to a reduction in the volumetric heating value of the air/fuel mixture.

\subsection{Ignition Energy}

\subsubsection{Low Ignition Energy}

Hydrogen has very low ignition energy. The amount of energy needed to ignite hydrogen is about one order of magnitude less than that required for gasoline. This enables hydrogen engines to ignite lean mixtures and ensures prompt ignition.

Table 1. some properties for hydrogen and other fuels under stoichiometric conditions

\begin{tabular}{|c|c|c|c|c|c|}
\hline Properties & Hydrogen & Methanol & Methane & Gasoline & Unit \\
\hline Flammability limits & $4-75$ & $7-36$ & $5-15$ & $1.0-7.6$ & Vol. \% \\
\hline Minimum ignition energy. & 0.02 & - & 0.29 & 0.24 & $\mathrm{~mJ}$ \\
\hline Flame temperature & 2045 & - & 1875 & 2200 & ${ }^{\circ} \mathrm{C}$ \\
\hline Auto ignition temperature & 585 & 385 & 540 & $230-500$ & ${ }^{\circ} \mathrm{C}$ \\
\hline Diffusion coefficient & 0.61 & 0.16 & 0.20 & 0.05 & $10-3 \mathrm{~m} 2 / \mathrm{s}$ \\
\hline Maximum velocity of flame & 3.46 & - & 0.43 & - & $\mathrm{m} / \mathrm{s}$ \\
\hline
\end{tabular}

Unfortunately, the low ignition energy means that hot gases and hot spots on the cylinder can serve as sources of ignition, creating problems of premature ignition and flashback. Preventing this subject is one of the challenges associated with running an engine on hydrogen. The wide flammability range of hydrogen means that almost any mixture can be ignited by a hot spot.

\subsection{2 .High Auto ignition Temperature}

Hydrogen has a relatively high auto ignition temperature. This has important implications when a hydrogen-air mixture is compressed. In fact, the auto ignition temperature is an important factor in determining what compression ratio an engine can use, since rising temperature during compression is related to the compression ratio. The temperature rise is shown by the equation:

$$
T_{2}=T_{1}\left(\frac{V_{1}}{V_{2}}\right)^{\gamma-1}
$$

where:

$$
\begin{aligned}
& \frac{V_{1}}{V_{2}}=\text { the compression ratio, } \\
& T_{1}=\text { absolute initial temperature, } \\
& T_{2}=\text { absolute final temperature, } \\
& \gamma=\text { ratio of specific heats }
\end{aligned}
$$

The temperature may not exceed hydrogen's auto ignition temperature without causing premature ignition. Thus, the absolute final temperature limits the compression ratio. The high auto ignition temperature of hydrogen allows larger compression ratios to be used in a hydrogen engine than in a hydrocarbon engine.

\subsubsection{High Flame Speed}

Hydrogen has high flame speed at stoichiometric ratios. Under these conditions, the hydrogen flame speed is nearly an order of magnitude higher (faster) than that of gasoline. This means that hydrogen engines can more closely approach the thermodynamically ideal engine cycle. At leaner mixtures, however, the flame velocity decreases significantly.

\section{Injection Systems}

\subsection{Port Injection Systems}

The port injection fuel delivery system injects fuel directly into the intake manifold at each intake port, rather than drawing fuel in at a central point. Typically, the hydrogen is injected into the manifold after the beginning of the intake stroke. At this point conditions are much less severe and the probability for premature ignition is reduced [22].

In port injection, the air is injected separately at the beginning of the intake stroke to dilute the hot residual gases and cool any hot spots. Since less gas (hydrogen or air) is in the manifold at any one time, any pre-ignition is less severe. The inlet supply pressure for port injection tends to be higher than for carburetted or central injection systems, but less than for direct injection systems.

The constant volume injection (CVI) system uses a mechanical cam-operated device to time the injection of the hydrogen to each cylinder.

The electronic fuel injection (EFI) system meters the hydrogen to each cylinder. This system uses individual electronic fuel injectors (solenoid valves) for each cylinder and is plumbed to a common fuel rail located down the centre of the intake manifold. Whereas the CVI system uses 
constant injection timing and variable fuel rail pressure, the EFI system uses variable injection timing and constant fuel rail pressure.

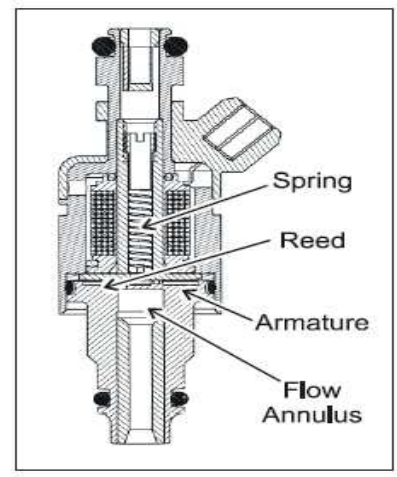

Figure 1. Electronic fuel injector

\subsection{Direct Injection Systems}

More sophisticated hydrogen engines use direct injection into the combustion cylinder during the compression stroke. In direct injection, the intake valve is closed when the fuel is injected, completely avoiding premature ignition during the intake stroke. Consequently the engine cannot backfire into the intake manifold.

The power output of a direct injected hydrogen engine is $20 \%$ more than for a gasoline engine and $42 \%$ more than a hydrogen engine using a carburettor. While direct injection solves the problem of pre-ignition in the intake manifold, it does not necessarily prevent pre-ignition within the combustion chamber. In addition, due to the reduced mixing time of the air and fuel in a direct injection engine, the air/fuel mixture can be non-homogenous. Studies have suggested this can lead to higher NOx emissions than the non-direct injection systems. Direct injection systems require a higher fuel rail pressure than the other methods.

\section{Internal Geometry Determination}

The nozzle geometry has an important influence on injection process and combustion development [23,25]. For this reason, the silicone methodology [26] has been employed to get information about the internal geometry of the nozzles used for this study.

This technique consists on the application of a special silicone in order to obtain a mould of the nozzle. Once the moulds are prepared, pictures are obtained using a Scanning Electron Microscope (SEM). These images are processed using CAD software in order to evaluate nozzle geometric parameters such as inlet and outlet diameter or upper and lower rounding radii.

The degree of conicity can also be evaluated for each nozzle and each hole by the k-factor, defined as:

$$
k-\text { factor }=\frac{D_{i}(\mu m)-D_{o}(\mu m)}{10}
$$

In here $D_{i}$ is inlet diameter of nozzle orifice and $D_{o}$ is outlet of nozzle orifice.

\section{Hydrogen Gas Mixtures}

Hydrogen can be used advantageously in internal combustion engines as an additive to a hydrocarbon fuel. Hydrogen is most commonly mixed with high pressure natural gas for this purpose since both gases can be stored in the same tank. If hydrogen is blended with other fuels, it usually has to be stored separately and mixed in the gaseous state immediately before ignition. In general, it is impractical to use hydrogen in conjunction with other fuels that also re-quire bulky storage systems, such as propane.

Gaseous hydrogen cannot be stored in the same vessel as a liquid fuel. Hydrogen's low density will cause it to remain on top of the liquid and not mix. Furthermore, liquid fuels are stored at relatively low pressures so that very little hydrogen could be added to the vessel.

Liquid hydrogen cannot be stored in the same vessel as other fuels. Hydrogen's low boiling point will freeze other fuels resulting in fuel "ice". Hydrogen can be used in conjunction with compact liquid fuels such as gasoline, alcohol or diesel provided each are stored separately. In these applications, the fuel tanks can be formed to fit into unused spaces on the vehicle.

Existing vehicles of this type tend to operate using one fuel or the other but not both at the same time. One advantage of this strategy is that the vehicle can continue to operate if hydro-gen is unavailable.

Hydrogen cannot be used directly in a diesel (or "compression ignition") engine since hydrogen's auto ignition temperature is too high (this is also true for natural gas). Thus, diesel engines must be outfitted with spark plugs or use a small amount of diesel fuel to ignite the gas (known as pilot ignition). Although pilot ignition techniques have been developed for use with natural gas, no one is currently doing this with hydrogen.

\section{Emissions}

The combustion of hydrogen with oxygen produces water as its only product:

$$
2 \mathrm{H}_{2}+\mathrm{O}_{2}=2 \mathrm{H}_{2} \mathrm{O}
$$

The combustion of hydrogen with air however can also produce oxides of nitrogen $\left(\mathrm{NO}_{\mathrm{x}}\right)$ :

$$
\mathrm{H}_{2}+\mathrm{O}_{2}+\mathrm{N}_{2}=\mathrm{H}_{2} \mathrm{O}+\mathrm{N}_{2}+\mathrm{NOx}
$$

The oxides of nitrogen are created due to the high temperatures generated within the combustion chamber during combustion. This high temperature causes some of the nitrogen in the air to combine with the oxygen in the air. The amount of NOx formed depends on the air/fuel ratio, the engine compression ratio, the engine speed, the ignition timing, whether thermal dilution is utilized. 
In addition to oxides of nitrogen, traces of carbon monoxide and carbon dioxide can be present in the exhaust gas, due to seeped oil burning in the combustion chamber.

\section{Maximum Power Output}

Theoretically, in a hydrogen engine, maximum power output depends on the air/fuel ratio and fuel injection method used.

As, in the some studies show that the stoichiometric air/fuel ratio for hydrogen is 34:1. At this air/fuel ratio, hydrogen will displace $29 \%$ of the combustion chamber leaving only $71 \%$ for the air. As a result, the energy content of this mixture will be less than it would be if the fuel were gasoline (since gasoline is a liquid, due to it occupies a very small volume of the combustion chamber, and thus allows more air to enter).

\section{Comparison of Blend of Methane - Hydrogen}

While investigating the advantages and disadvantages of fuels and their mixtures such as methane and hydrogen, the point that should be considered the criteria such as efficiency, performance and emission. Studies demonstrate to conduct comparisons should have identical conditions. In comparisons, there are a lot of effective parameters such as compression ratio, engine volume, temperature, pressure, engine power, load and spark timing and even different measurement devices are used in each study. Also, it is more suitable to compare on environmental and technical basis while comparisons are made.

Nitrogen oxides (NOx) refer to a mixture of two compounds: Nitrogen monoxide (NO) and Nitrogen dioxide (NO2). Nitrogen monoxide is a colourless gas where nitrogen dioxide absorbs sunlight strongly at short wavelengths According to Refs. [27, 28, 29] and Bauer and Forest [30] (there is no data value in graphics), with increasing $\mathrm{H} 2$ percentage, BSNOx (Break specific production of nitric oxides, $\mathrm{g} / \mathrm{kWh}$ ) values are increasing. If a catalytic converter is used, NOx emission values can be decreased to extremely low levels.

The predicted emission of NOx and CO from the model with experiment data is compatible well and the following characters are well modelled by the simulation. When the load changes for HCNG and CNG fuel from $15 \%$ to $20 \%$, the emission of $\mathrm{CO}$ and $\mathrm{NOx}$ decreases and increases respectively. The emission of $\mathrm{CO}$ in the $\mathrm{HCNG}$ engine is much lower than NOx. And consequently, with increasing of hydrogen fraction, Enhancement of chemical reaction with hydrogen addition, increase of $\mathrm{H}, \mathrm{O}$ and $\mathrm{OH}$ radical mole fractions will be in the flame and Strong correlation is found between the burning velocity and the maximum radical concentrations of $\mathrm{H}$ and $\mathrm{OH}$ in the reaction zone of the premixed flames $[31,32]$.

Also, the results showed that hydrogen and CNG blends improved engine performance, especially brake efficiency, particularly for the highest hydrogen content and low loads, with fuel consumptions on energy basis over NEDC (the New European Driving Cycle) 2.5\%, 4.7\% and 5.7\% lower than $\mathrm{CNG}$, for HCNG 10, 20 and 30 respectively.

\section{Experimental Setup}

Experiments were conducted at initial pressure of 0.1 $\mathrm{MPa}$ and initial temperature of $303 \mathrm{~K}$. Purities of methane and hydrogen in the study are $99.9 \%$ and $99.995 \%$, respectively.

The volumetric percentage of hydrogen in the fuel blends $\left(X_{\mathrm{H}_{2}}\right)$ is defined as,

$$
X_{H_{2}}=\frac{V_{H_{2}}}{V_{C_{4}}+V_{H_{2}}}
$$

Where $V_{\mathrm{CH}_{4}}$ and $V_{\mathrm{H}_{2}}$ are the volume fraction of methane and hydrogen in the fuel blends, respectively. The equivalence ratio $(\phi)$ is defined as,

$$
\phi=\frac{F / A}{(F / A)_{s t}}
$$

Where $F / A$ is fuel-air ratio and $(F / A)_{s t}$ refers to the stoichiometric value of $F / A$.

For stoichiometric methane-air and hydrogen-air mixture combustion, the chemical formulas are as follows:

$$
\begin{gathered}
\mathrm{CH}_{4}+2\left(\mathrm{O}_{2}+3.76 \mathrm{~N}_{2}\right)=\mathrm{CO}_{2}+2 \mathrm{H}_{2} \mathrm{O}+2 \times 3.76 \mathrm{~N}_{2} \\
\mathrm{H}_{2}+0.5\left(\mathrm{O}_{2}+3.76 \mathrm{~N}_{2}\right)=\mathrm{H}_{2} \mathrm{O}+0.5 \times 3.762 \mathrm{~N}_{2}
\end{gathered}
$$

Mixture can be expressed as,

$$
\left(1-X_{H_{2}}\right) C_{4}+X_{H_{2}} . H_{2}+\left(\frac{2}{\phi}\left(1-X_{H_{2}}\right) \frac{X_{H_{2}}}{2 \phi}\right)\left(O_{2}+3.76 N_{2}\right)
$$

\subsection{Engine Dynamometer Controller and Software}

For the engine performance testing, the parameters of the operations engine such as percentage of throttle opening, engine speed and dynamometer load are controlled by using CP Engineering Cadet V16 software and engine controller. The software and engine controller are able to run the engine with close loop system and record the engine performance data either by manually or automatic engine testing. However, due to the engine testing are affected by the environment conditions such as environment humidity, temperature and pressure. Hence, the ISO 1585 engine correction factor as shown in equation 1 to 3 are used for the calculation of brake power and torque in the experiments.

$$
\text { vapourpressure }=2.17182819\left(\frac{-5293.7}{273+\text { RHTemp }}+18.927\right) \times\left(\frac{R H \%}{100}\right)
$$


Where:

RHTemp $=$ Temperature of measured air $(\mathrm{oC})$,

$R H \%=$ Relative humidity of measured air (\%)

Corrected Barometer $=$ Measured Barometer - Vapour Pressure

And, Corrected Barometer $=$ Corrected Barometric Pressure $(\mathrm{kPa})$

Measured Barometer $=$ Measured Barometric pressure $(\mathrm{kPa})$

CorFac $_{\text {ISO } 1585}=\left(\frac{273+\text { AirInletTemp }}{298}\right)^{0.6} \times\left(\frac{99}{\text { CorrectedBarometer }}\right)^{1.2}$ (oC)

Also, Air Inlet Temp $=$ Measured air intake temperature

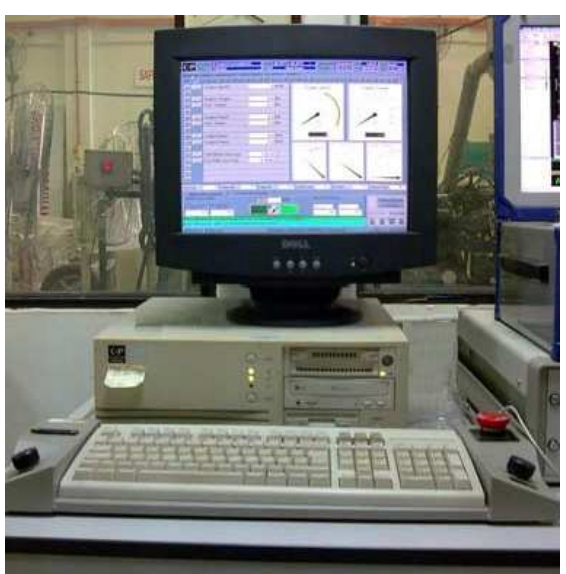

Figure 2. CP Engineering Cadet V16 software and engine controller

\subsection{Electronic Control Unit (ECU)}

To get the optimal engine performance and exhaust emissions results of engine testing, a programmable ECU should be installed and used to control and tune the engine.

The amount of the CNG fuels that is injected to the cylinder will affect the quality of air-fuel mixture and subsequently will affect the power and emissions performance of the engine. In additions, the ignition timing was varied from 15 to $20 \mathrm{o}$ BTDC to get the optimal MBT of DI performance results.

\section{Conclusions}

\subsection{Numerical and Experimental}

The results show that HCNG blends improved engine brake efficiency, particularly at low loads and with increasing hydrogen content in blend from 10 to $30 \%$, NOx emissions increase of about $4 \%$ to $20 \%$ due to the higher in-cylinder gas temperatures. Also in this engine, investigations show that use of about $10 \%$ EGR for HCNG blends, decrease NOx emission highly and fuel consumption compared with natural gas.

The fundamental effect of hydrogen on methane combustion was investigated for a fixed excess air ratio of
1.2 and a spark timing of 14CA (Crank Angle) BTDC (Before Top Dead Centre), with an accompanying reduction in ignition delay. By varying the excess air ratio, hydrogen was demonstrated to highly effect in extending the lean operating limit. The applied DOE (Design of Experiment) method to study MBT (Maximum Brake Torque) spark timing for various excess air ratios and hydrogen contents show that the maximum brake torque could be achieved under leaner burning conditions by increasing the hydrogen content.

Enhancement of chemical reaction with hydrogen addition, increase of $\mathrm{H}, \mathrm{O}$ and $\mathrm{OH}$ radical mole fractions will be in the flame and Strong correlation is found between the burning velocity and the maximum radical concentrations of $\mathrm{H}$ and $\mathrm{OH}$ in the reaction zone of the premixed flames.

The fundamentals of the thermodynamic model, the turbulent flame propagation model and related equation consider that the most important factor influencing the applicability of the model for variable hydrogen blending ratio is the laminar flame speed.

The rate of production analysis and the effect of hydrogen addition on the reaction of methane-air mixtures combustion show that the mole fractions of major species $\mathrm{CH} 4, \mathrm{CO}$ and $\mathrm{CO} 2$ were decreased while their normalized values were increased as hydrogen are added. The rate of production of the dominant reactions contributing to $\mathrm{CH} 4$, $\mathrm{CO}$ and $\mathrm{CO} 2$ show a remarkable increase as hydrogen is added. The role of $\mathrm{H} 2$ in the flame will change from an intermediate species to a reactant when hydrogen fraction in the blends exceeds $20 \%$.

Experimental results show that percentage of hydrogen in the NG increases the burning velocity of NG and decreases the optimal ignition timing to obtain the maximum indicated mean pressure of the engine running with these mixtures. The indicated efficiency rises as the percentage of hydrogen in the $\mathrm{NG}$ increases and $\mathrm{CO}$ emissions are almost unappreciable because the tests of this work are developed in lean combustion conditions and the $\mathrm{CO}$ oxidizes totally. With respect to NO emission and the maximum temperature of the burned mixture, as the percentage of hydrogen in the NG rises, the NO emission increases due to the higher burned temperature.

\section{References}

[1] Orhan A, Zafer D. Internal combustion engines fuelled by natural gas-hydrogen mixtures. Int J Hydrogen Energy 29, pp. $1527-1539,2004$.

[2] Ristovski Z, Morawska L, Ayoko GA, Johnson G, Gilbert D, Greenaway C. Emissions from a vehicle fitted to operate on either petrol or compressed natural gas. Sci Total Environ 323:179-94, 2004.

[3] Mello P, Pelliza G, Cataluna R, da Silva R. Evaluation of the maximum horsepower of vehicles converted for use with natural gas fuel. Fuel 85:2180-6, 2006. 
[4] GM well-to-wheel analysis of energy use and greenhouse gas emissions of advanced fuel/vehicle systems-a European study. Ottobrunn, Germany: GM, LBST. Available from:http://www.lbst.de/gm-wtw; 2002.

[5] Biagio M, Andrea U. Numerical investigation on the effects of natural gas and hydrogen blends on engine combustion. Int J Hydrogen Energy 34 , pp.4626 - 4634, 2009.

[6] Bauer CG, Fosest TW. Effect of hydrogen addition on the performance of methane-fuelled vehicles. Part I: effect on S.I. engine performance. Int J Hydrogen Energy 26:55-70, 2001.

[7] Wang J, Huang Z, Zheng J, Miao H. Effect of partially premixed and hydrogen addition on natural gas direct injection lean combustion. Int $\mathrm{J}$ Hydrogen Energy 34:9239-47, 2009.

[8] $\mathrm{Hu} \mathrm{E}$, Huang Z, Liu B, Zheng J, Gu X, Huang B. Experimental investigation on performance and emissions of a spark ignition engine fuelled with natural gas- hydrogen blends combined with EGR. Int $\mathrm{J}$ Hydrogen Energy 34:528-39, 2009

[9] Wang J, Huang Z, Miao H, Wang X, Jiang D. Characteristics of direct injection combustion fuelled by natural gashydrogen mixtures using a constant volume vessel. Int J Hydrogen Energy 33:1947-56, 2008.

[10] Wang J, Huang Z, Miao H, Wang X, Jiang D. Study of cyclic variations of direct-injection combustion fuelled with natural gas-hydrogen blends using a constant volume vessel. Int J Hydrogen Energy 33:7580-91, 2008.

[11] Wang J, Chen H, Liu B, Huang Z. Study of cycle-by-cycle variations of a spark ignition engine fuelled with natural gas- hydrogen blends. Int J Hydrogen Energy 33:4876-83, 2008.

[12] Zareei J, Yusoff A, Shahrir A, Faizal M. Comparing the Effects of Hydrogen Addition on Performance and Exhaust Emission in a Spark Ignition Fueled with Gasoline and CNG. Applied Mechanics and Materials. 165: 120-124, 2012.

[13] Hoekstra RL, Collier K, Mulligan N, Chew L. Experimental study of a clean burning vehicle fuel. Int J Hydrogen Energy 20:737-45, 1995 .

[14] Nagalingam B, Duebel F, Schmillen K. Performance study using natural gas, hydrogen-supplemented natural gas and hydrogen in AVL research engine. Int $\mathrm{J}$ Hydrogen Energy8:715-20, 1983.

[15] Dimopoulos P, Bach C, Soltic P, Boulouchos K. Hydrogen and natural gas blends fuelling passenger car engines: combustion, emissions and well-to-wheels assessment. Int J Hydrogen Energy 33(23):7224-36, 2008.

[16] Apostolescu N, Chiriac R. A study of combustion of hydrogen-enriched gasoline in a spark ignition engine. SAE paper no. 960603 .

[17] Bade Shrestha SO, Karim GA. A predictive model for gas fuelled spark ignition applications. SAE Paper No. 1999-01-3482.

[18] Ramos JI. Internal combustion engine modelling. New York: Hemisphere Publication Corporation; 1989.

[19] Hamori F. Exploring the limits of hydrogen assisted jet ignition. PhD Thesis, the University of Melbourne; 2006.

[20] GT-POWER. User's manual Version 6.2. Gamma Technologies; 2006.

[21] Heywood JB. Internal combustion engine fundamentals. International ed. Singapore: McGraw-Hill; 1988.

[22] How HG, Taib IM, Shahrir A, Yusoff A and Azhari Sh. Experimental Investigation of Performance and Emissions of a Sequential Port Injection Compressed Natural Gas Converted Engine. SAE paper 2009-32-0026 / 20097026.

[23] Kampmann S, Dittus B, Mattes P, Kirner M. The influence of hydro grinding at VCO nozzles on the mixture preparation in a DI diesel engine, SAE paper 1996; 960867.

[24] Ganippa LC, Andersson S, Chomiak J. Combustion characteristics of diesel sprays from equivalent nozzles with sharp and rounded inlet geometries. Combust Sci Technol 175:1015-32, 2003.

[25] Park SW, Reitz RD. Modelling the effect of injector nozzle-hole layout on diesel engine fuel consumption and emissions. J Eng Gas Turb Power 30:032805 (3), 2008.

[26] Macián V, Bermúdez V, Payri R, Gimeno J. New technique for determination of internal geometry of diesel nozzles with the use of silicone methodology. Exp Tech 27:39-43, 2003.

[27] Swain MR, Yusuf MJ, Dulger Z, Swain MN. The effects of hydrogen addition on natural gas engine operation. SAE paper 1993; 932775.

[28] Hoekstra RL, Collier K, Mulligan N, Demonstration of hydrogen mixed gas vehicles, 10th World hydrogen Energy Conference, Cocoa Beach, USA, June 20-24, 1994.

[29] Larsen JF, Wallace JS. Comparison of emissions and efficiency of a turbocharged lean-burn natural gas and hythane -fueled engine. J Eng Gas Turbines Power 119:218-26, 1997.

[30] Bauer CG, Forest TW. Effect of hydrogen addition on performance of methane-fueled vehicles. Part I: effect on S.I. engine performance. Int J Hydrogen Energy 26:55-70, 2001.

[31] Yujun W, Xin Zh, Congxin Li, Jianfeng Wu. Experimental and modelling study of performance and emissions of SI engine fueled by natural gas-hydrogen mixtures. Int $\mathrm{J}$ hydrogen energy 35, pp.2680-2683, 2010.

[32] Erjiang Hu, Zuohua Huang, Jiajia He, Chun Jin, Jianjun Zheng. Experimental and numerical study on laminar burning characteristics of premixed methane-hydrogen-air flames. Int J Hydrogen Energy 34, 4876-488, 2009. 